\title{
Sexualidad, psicoanálisis y crítica feminista
}

Las verdades que hacen a los hombres libres son para la mayoria, las que prefieren no oír.

Hebert Agar

\section{Introducción: los maestros de la sospecha}

Al final del siglo XIX y comienzos del XX destacan dos escuelas importantes de pensamiento: el marxismo y el psicoanálisis. Ambas escuelas forjarán conceptos y teorías sobre las cuales se asientan buena parte de nuestras interpretaciones contemporáneas sobre la realidad humana. Aquí no pretendemos estudiarlas a fondo, sino hacer uná aproximación somera para ver qué representan desde un punto de vista de género.

Se ha llamado "maestros de la sospecha" al trío de autores que forman Marx, Nietzsche y Freud, y han recibido este apelativo para enfatizar la ruptura de la filosofía contemporánea con la filosofía moderna, que culmina en Hegel. Hegel había dicho "todo lo real es racional". Ellos sospechan que la razón no es ni mucho menos la parte más determinante del ser humano, sino que hay otros aspectos - posiblemente ocultos- que tienen una importancia hasta entonces totalmente opacada: la voluntad para Nietzsche, la sociedad y la economía para Marx, el inconsciente para Freud.

Se trata de una respuesta a las ciencias decimonónicas que buscará aportar nueva luz sobre el terreno de la moral (Nietzsche), del conocimiento de la economía y la sociedad (Marx) y de la psicología (Freud). Vertebrarán sus respectivas concepciones del ser humano alrededor del supuesto de que la explicación consciente - racional- que las personas dan de su conducta, es sólo una máscara que encubre los verdaderos motivos que escapan a la conciencia. El ser humano, vendrán a decir, dista mucho de poderse definir, según la clásica expresión, como "animal racional". La reducción del espíritu a razón es una auténtica 
aberración que provoca la destrucción de los sentimientos y la sofocación de los instintos, que son tan parte del ser humano como la capacidad de razonar.

Nietzsche estudió la moral. Occidente huele a podrido: hay una corrupción de las costumbres. ¿Cómo hacer para no morir ahogados por una moral que nos asfixia? Hay que cambiar este estado de cosas. Esta misma percepción de que las cosas andan demasiado turbias es la que hace acuñar a Marx su concepto de ideologia. Los hombres viven con una conciencia falsa, la realidad dista mucho de ser lo que aparenta. Continuar viviendo en el autoengaño no nos va ayudar a cambiarla. La razón, aplicada acríticamente, en lugar de iluminar, lo que hace es oscurecer, encubrir los verdaderos motivos del comportamiento. Freud intentará mostrar cuáles son los motivos ocultos del comportamiento humano, motivos que va a hallar en el inconsciente y que, según él, se ocultan a la conciencia racional.

Marx acentúa mucho la dimensión social, analizará la vida humana como vida colectiva (clase social, familia, especie). Freud, en cambio, va a subrayar más el aspecto individual. El es un científico médico y su pregunta es ihasta qué punto el individuo puede ser totalmente libre, responsable? ¿Qué factores determinan el comportamiento? ¿Cuál es el funcionamiento del psiquismo humano?

Todas estas preguntas plantean innumerables cuestiones y enfoques para la visión de los géneros. No vamos a tratar de agotarlas todas, sino de señalar las que puedan resultar más interesantes. Para ello se hará necesario hacer un breve recorrido por los postulados principales de la teoría freudiana, pero no pasaremos a ello sin antes mencionar brevemente cual es la situación histórica en la que se halla occidente en el período que nos ocupa: por una parte, la eclosión del proceso de industrialización, la incorporación masiva de las mujeres proletarias al mundo del trabajo asalariado y el crecimiento de los movimientos que reivindicaban derechos civiles y políticos para las mujeres.

En tiempos de Freud, el feminismo experimenta un auge, dato que es importante advertir para contextualizar sus escritos en el tiempo que le tocó vivir, y para valorarlo en su justa situación. El feminismo se había introducido en las filas del psicoanálisis en los últimos años de su vida, y éste luchó activamente contra la mayor parte de las críticas que se le hacían desde esta perspectiva, a veces hasta de un modo un tanto pintoresco'.

\section{La psicología antes de Freud}

La psicología antes de Freud tenía dos postulados: en primer lugar, que el psiquismo es memoria, entendimiento y voluntad; en segundo lugar, que el alma y la conciencia se identifican. Respecto al primer postulado señalemos brevemente que se suponía que el entendimiento captaba realidades, que la memoria las retenía y que la voluntad servía para actuar en consecuencia. Dentro de esta concepción no ocupaban ningún lugar relevante los afectos o sentimientos, ni estaba clara la 
relación alma-cuerpo. Los sentimientos se interpretaban como "pasiones", es decir, como elementos pasivos y perturbadores que el alma tenía que controlar. No se tomaban en cuenta como elementos básicos en la conformación de la personalidad. En contraste, la teoría freudiana verá en la afectividad el centro de estructuración de la personalidad y la fuente de todos los trastomos psicológicos y sociales, si ésta no es adecuadamente satisfecha.

El segundo postulado también lo va a cuestionar Freud seriamente. Va a decir que hay un "lado oscuro" del alma, que es tanto o más importante que la llamada "conciencia": el área del deseo, la cual no sale a la luz más que cuando la dejamos, aunque a veces sale sin querer.

La psiquiatría estudia y trata de curar las enfermedades mentales, que se definen como aquellos trastomos de tipo psíquico que no obedecen a causas orgánicas. Ante un transtomo psíquico (un delirio, una idea obsesiva...) o ante un trastomo funcional (perturbaciones en la visión o en la locomoción) sin justificación orgánica alguna, el psiquiatra va a preguntarse inmediatamente por su causa. La psiquiatría clásica afirmaba o bien que tenía origen orgánico, o que simplemente eran invenciones del paciente. Freud, con un espíritu abierto, tomó en serio estas enfermedades, las estudió y se dedicó a sacar un sinnúmero de consecuencias, no sólo aplicables a la personalidad enferma, sino también a la que está categorizada como "sana". Precisamente, todos los descubrimientos freudianos entomo a la formación del psiquismo, se basan en su experiencia clínica. Ello no significa necesariamente que sus teorías estén "comprobadas", o que sean totalmente "científicas", sino sólo que parten de observaciones que él realizaba dentro de su práctica médica. El psicoanálisis comenzó por ser un método o procedimiento para curar la neurosis, especialmente la histeria, pero pronto aparece con una segunda significación: como hipótesis o modelo explicativo de la estructura y composición de nuestra vida psíquica, como hermenéutica de los actos humanos.

Sus planteamientos tienen pretensiones de universalidad, pero ésta se ha hallado cuestionada por múltiples críticas, que le han achacado el extrapolar a todo psiquismo humano lo que serían simplemente conflictos o conductas provocadas por la sociedad vienesa de su época, y más concretamente por la clase burguesa de esta sociedad a comienzos de siglo. Sin embargo, antes de analizar las críticas a Freud, bien vale la pena estudiar los puntos clave de esta doctrina, pues en ella podemos hallar perspectivas y enfoques que tal vez pueden resultar, a la postre, universalizables.

\section{La teoría del inconsciente y el desarrollo evolutivo de la psique}

En sus prácticas de medicina en un psiquiátrico, Freud fue instruido en la hipnosis por su maestro Joseph Breuer. La comprobación que una persona que ha ejecutado previamente una orden en estado hipnótico manifiesta, una vez despierta, ignorar siempre el motivo por el cual realiza el acto ordenado, o da a este una explicación racional que nada tiene que ver con el motivo que le indujo a 
ejecutar la orden, le sugirió la idea de que los verdaderos motivos de nuestros actos escapan siempre a la conciencia del individuo. Este concepto de inconsciente es la clave del sistema freudiano, y no es fácil de definir. De momento nos limitaremos a señalar que las leyes de la sociedad las adquirimos de modo inconsciente, y que lo inconsciente es un trasfondo omnipresente que ejerce continua influencia causal sobre el pensamiento y la conducta. Se puede definir también como un sistema de actos. El inconsciente es, además, el terreno de la libido, el lugar natural —por así decirlo- de las pulsiones. El inconsciente está constituido por aquellos deseos que se reprimen a la luz de las exigencias de la realidad, por ejemplo, los desẹos incestuosos de la infancia. "Lo inconsciente en la vida mental es también lo infantil" - dice Freud. Es el núcleo primario de lo que constituye la personalidad. Freud establece cuatro presupuestos básicos: (1) Que la motivación humana está enraizada en el inconsciente, cuyas fuentes inagotables son los eventos y las relaciones que ocurren en los primeros años de vida. (2) Que la necesidad sexual constituye, desde el inicio de la vida, la mayor dinámica que motiva el funcionamiento humano. (3) Que el desarrollo infantil ocurre en un conjunto de etapas en secuencia. (4) Que los seres humanos son bisexuales innatos y que se vuelven apropiados heterosexuales, en contingencia con una secuencia específica de desarrollo que involucra las acciones y reacciones de los padres durante la infancia temprana.

Al nacer, todos los infantes - considera Freud- poseen un instinto sexual general no orientado, al cual él denominó libido. Esta libido experimenta múltiples variaciones objetales evolutivas que se concretan en las siguientes fases o etapas del desarrollo:

ORAL La gratificación primaria es encontrada en la liberación del hambre a través del amamantado. Búsqueda de placer por la boca.

ANAL $\quad 2^{2}$ y 3er año de vida: la gratificación está centrada en el control sobre sus entrañas. Esta etapa surge en la medida en que los niños son apreciados y reconocidos por sus padres por el hecho de desarrollar ese control.

FÁliCA Entre los 3 y 4 años la gratificación cambia hacia los genitales, en la medida en que los niños descubren la masturbación.

LATENTE Cerca de los 6 años cesan de mostrar su sexualidad, que permanecerá latente varios años. El placer deriva del mundo externo: la curiosidad, el conocimiento como satisfacciones sustitutas.

GENITAL En la pubertad reemerge la necesidad sexual. El placer deriva de las relaciones sexuales maduras con el compañero (a) del sexo opuesto. $\mathrm{El}$ autoerotismo o narcisismo del período pregenital deriva hacia el amor a otros e incluye motivos altruistas. A la dependencia parental sucede la emancipación. 
Este planteamiento ha llevado a algunos críticos a tildar a Freud de "naturalista" o "evolucionista", puesto que dada su forma de abordar la psicología en correlación a ciertos cambios aparentemente biológicos, parece sugerir un regreso al biologicismo del que pretende desmarcarse explícitamente. Sin embargo, contra esta acusación se ha señalado también que "todas estas etapas sólo son importantes en el contexto de los esfuerzos del niño por encontrarse a sí mismo, es decir, por descubrir dónde encaja en el esquema de las cosas. Primero tiene que descubrir su lugar mediante su relación con los objetos; después, como objeto él mismo para otros"2. El complejo de Edipo jugará un papel importante dentro de estas etapas. Si para cierta corriente de críticas Freud continua siendo un naturalista, para otra éste habría asestado un golpe mortal al naturalismo al establecer la profunda heteronomía entre la pulsión y su objeto. "La sexualidad humana es caprichosa, variable, múltiple, a veces silenciosa, alejándose de la consistencia y ritmo regular que caracteriza el celo animal"3.

Lo que contiene el inconsciente no es el "instinto en su estado puro", propiamente, sino ideas o representaciones del instinto vinculadas a impulsos que buscan descargar su energía, impulsos llenos de deseo a los que se niega el acceso a la conciencia. Lo inconsciente es, pues, una estructura de representaciones. Subrayar esto sirve para aclarar que Freud distinguió claramente entre el inconsciente y cualquier parentesco inmediato de éste con los instintos animales, aunque éstos pudieran constituir un núcleo de algún tipo ${ }^{4}$ que no acaba de definir con precisión.

Desde un punto de vista filosófico cabría preguntamos si la primariedad del subconsciente lo constituyen realmente ideas o representaciones o si es que tal vez hay contenidos y formas pre-cognitivas y pre-verbales, aunque no necesariamente "naturales", que determinan de manera decisiva el subconsciente, o más aún, constituyen su substrato más básico. Si fuera así, sería posible hacer una especie de psicoanálisis social que no tendría necesariamente que seguir las pautas del análisis individual, tal como lo trabajan los psicoanalistas, ni pretendería acceder a un supuesto "inconsciente colectivo" a la manera de un macrosujeto, sino que podría analizar mucho más cuidadosamente las formas de trato, sea este físico, económico, o verbal que existen entre los seres humanos y que, por ende, son responsables de buena parte de nuestra conducta. Pero esto sería ya una cuestión que nos llevaría más lejos de los puntos de simple presentación que pretendemos abordar aquí.

\section{La estructura tripartita de la personalidad}

En la concepción psicoanalítica, lo consciente no representa más que la superficie de la estructura psíquica, que en su mayor parte es inconsciente. Las pulsiones reprimidas en el inconsciente ejercen presión para expresarse y se manifiestan en los sueños o en los síntomas neuróticos. 
La personalidad está integrada por 3 instancias:

1. SUPERYO: Es la dimensión moral del sujeto. Representa lo ideal. En el superyo se hallan, según Freud, los principios de la cultura y la civilización.

2. YO: Está gobernado por el principio de realidad. Su objetivo es suavizar la descarga de energía del ello hasta que se presente el objeto real que pueda satisfacer tal necesidad en una situación socialmente aceptable. La intervención del principio de realidad del yo no supone que el principio de placer del ello sea anulado. Sólo se suspende temporalmente en interés de la realidad. El yo actúa, pues, de intermediario entre el ello ý el mundo externo.

3. ELLO: Regido por el principio de placer. Está formado por energía instintiva y es inconsciente. Distingue eros (libido) y thanatos (pulsión de muerte). Es el fundamento sobre el que se edifica la personalidad; la rama más arcaica y primitiva del ser humano. El ello conserva su carácter infantil durante toda su vida. No piensa, sólo desea, es exigente, irracional, impulsivo, asocial y egoísta. Es la parte más "asocial" de la estructura.

Aquellos deseos del ello que son fundamentalmente incompatibles con las normas morales del superyo son reprimidas, son abandonadas en el subconsciente. Una represión es un mecanismo inconsciente que impide a una pulsión llegar a la conciencia. Freud, para explicarlo, recurría a un ejemplo: es como si individuos sucios, desnudos y peludos (los instintos) pretendieran salir de una covacha oscura (el inconsciente) para subir a los salones (la conciencia) donde se celebra una elegante fiesta. Entre la covacha oscura y el salón iluminado, en la penumbra, se ocultan multitud de policías: el superyo. Cuando se produce la represión, estos impiden que los individuos sucios entren en el limpio salón, no quedándoles más remedio que regresarse a la covacha (inconsciente). Pero los elegantes protagonistas de la fiestas ignoran, en el salón, todo lo ocurrido.

El sujeto no es, pues, consciente de los impulsos que tiene reprimidos. Estos están en el inconsciente. Tiene estos impulsos sin saberlo. Una acumulación de deseos reprimidos puede originar una enfermedad psíquica: la neurosis. Esta enfermedad produce angustia y un profundo estado de debilidad y agotamiento. Para protegerse de los embates de los impulsos incontrolados y facilitar la adaptación a la realidad, el psiquismo posee ciertos mecanismos de defensa (racionalización, proyección, identificación, sublimación, compensación, regresión y fijación), que actúan como escudos de nuestra personalidad a quien los deseos hacen tanto fuerte como vulnerable.

Para Freud, decíamos, los motivos reales de nuestra conducta nunca son conscientes, siempre permanecen ocultos; sin embargo, hay formas colaterales de acceder a los misterios más profundos de nuestro ser. Una de estas formas es por medio de la interpretación de los sueños. Puesto que el id (ello) se manifiesta con símbolos, es decir, se esconde con materiales del yo, existe la posibilidad 
de descifrar estos símbolos y desvelar su contenido profundo o real. Esta es una de las tareas que el psicoanálisis se va a dar a sí mismo. Sueños típicos son la caída de dientes, ir desnudos, muerte de seres queridos, irse en el abismo, serpientes... A decir de Freud, muchos de ellos están relacionados con conflictos causados por el complejo de Edipo, y hay que tomar en cuenta que los sueños, además de ser expresión de deseos, son expresiones de angustias. Un sueño típico: soñamos que se muere nuestro ser más cercano. Esto es normal, todos hemos soñado esto. Nuestra interpretación es que lo soñamos porque tenemos miedo a perder este ser cercano porque lo queremos mucho, pero según Freud es todo lo contrario: expresa la angustia del desplazamiento y la necesidad que tenemos de hacerlo a un lado para cumplir nuestro propio deseo. Por esto son muy importantes los cuentos de hadas para los niños: Caperucita Roja, Cenicienta, Blancanieves, todos ellos expresan conflictos edipales y muestran o dan pistas sobre la manera de superar el conflicto. Le están diciendo al nin̄o: este conflicto es algo normal, algo que pasa, pero es una situación que se resuelve felizmente. De ahí que en los cuentos tenga que haber violencia, pues esta servirá para expresar las tensiones que se dan en nuestro interior de forma solapada. La vida onírica sería una manera que tiene el psiquismo de protegerse ante los sinsabores que nos da la vida en estado de vigilia.

\section{Enfermedades mentales y "normalidad"}

Freud señala que la así llamada "normalidad" no es tal, sino que tiene bastante de neurosis, psicosis y elementos patógenos en general. "La distinción entre salud nerviosa y neurosis queda reducida de este modo a una cuestión práctica y es determinada por el resultado, según quede o no al sujeto suficiente capacidad de goce y eficacia"s. La noción de normalidad no es, pues, si hemos de creerle a Freud, algo que el psicoanálisis busque establecer. Sin embargo en la práctica sí hallamos personas que "no se pueden manejar", que no logran sobrevivir con el mínimo de equilibrio. Cuando esta situación se hace insostenible decimos que hay "enfermedad". Uno de los méritos de Freud consiste precisamente en haber tomado en serio la enfermedad mental, y no sólo eso, sino que hace de ella la piedra de toque para la comprensión de la personalidad "sana". Es precisamente el estudio de las neurosis el que lo lleva a la comprensión de los procesos psíquicos "normales".

La neurosis es una enfermedad psicológica que se da como consecuencia de la represión de los instintos agresivos o sexuales. El yo tiene deseos, pero un superyo muy fuerte (debido a la familia, a la sociedad, a la religión....) no los reconoce. Entonces, el sujeto siente una angustia que no logra saber de donde viene, sufre depresión, temblores o malestares varios. Freud dice que no hay sociedad sin represión, por lo tanto esta es necesaria, pero cuando esta ahoga los instintos es malsana. La sociedad occidental es neurótica, como señala en $\mathrm{Ma}$ lestar en la cultura. Otra enfermedad mental típica es la psicosis, causada por la debilidad del superyo. Un psicótico no tiene normas de conducta, no sabe donde 
está el bien y el mal, no peca por mucha represión, sino por poca. En la esquizofrenia, en cambio, falla el principio de realidad. El esquizofrénico no tiene una personalidad maleable que le permita adaptarse a las diferentes circunstancias de la vida, sino que tiene varias personalidades. Por último, la histeria es un cuadro más complicado porque tiene variedad de síntomas, pero casi siempre van asociados a somatizaciones (disfunciones neurológicas tales como ceguera parcial, vómitos o afonías que no tienen aparentemente causa fisiológica). La personalidad histérica puede presentar infantilismo, falta de capacidad para tomar decisiones o un narcisismo exacerbado.

\section{La teoria de la bisexualidad}

Una de las primeras ideas y de las más firmes convicciones de Freud fue su noción sobre la bisexualidad". Según él, la diferenciación entre los sexos no surgía en forma precisa hasta la pubertad, aunque más tarde creyó detectar diferencias fundamentales en el proceso preedípico. $\mathrm{Ni}$ en el sentido psicológico ni en el biológico se encontraría en los seres humanos la masculinidad ni la feminidad en estado puro. Por el contrario, todo individuo presentaría una combinación de los rasgos de carácter pertenecientes a su propio sexo y al opuesto'. La vida sexual se iniciaría, según la versión más madura de Freud, con manifestaciones claras poco después del nacimiento, sólo que la sexualidad infantil tiene una naturaleza no estructurada y polimorfa. El abandono de esta indefinición a través de la superación del complejo de Edipo llevará, según él, a la consecución de la masculinidad y la feminidad heterosexual ${ }^{\sharp}$.

En el terreno de los grandes aportes de Freud a la psicología, en general, y a la teoría sexual, en particular, cabe señalar la diferenciación entre sexualidad y genitalidad. El primer concepto es más amplio e incluye muchas actividades que nada tienen que ver con los genitales. La vida sexual conlleva la función de obtener placer de las partes del cuerpo —una función que está relacionada, pero no unívocamente, con la reproducción- La sexualidad, por tanto, es mucho más amplia y compleja que la actividad genital; incumbe múltiples prácticas, representaciones y sentimientos que no están directamente relacionados con lo que se entendía tradicionalmente por "sexo".

Otro de los grandes aportes de su teoría, relacionado directamente con éste, es el de la centralidad del placer para el desarrollo de una personalidad y cultura no patológicas. El placer se obtendrá con la implicación del deseo en múltiples campos, no sólo dentro del campo de las actividades genitales. Los impulsos sexuales son extraordinariamente plásticos, pueden sublimarse y desviarse hacia objetivos claramente no sexuales, desviación que formará —a decir de nuestro autor- la base de la civilización y del logro cultural. Ahora bien, hay que tener cuidado en entender lo que quiere decir Freud para no desvirtuarlo, pues ello constituye uno de los rasgos clave de la teoría freudiana: el deseo, aunque pueda adquirir múltiples fines, es sexual; en última instancia: 
Aquellos críticos que proponen designar como energía vital general lo que Freud llama sexualidad o "libido", están invirtiendo sus investigaciones y sustentando una banalidad. Lo que Freud hizo fue todo lo contrario: afirmó que las "energías vitales" son sexuales [...]. Freud demostró que aquellos actos convencionalmente considerados como "inocentes" —actos aparentemente libres del placer y del deseo de placer- son, de hecho, actos sensuales. [...] Esto no significa afirmar que todo en todas partes es sexual. Freud se defendió siempre contra la acusación de pansexualismo. La teoría global freudiana de la vida psíquica es una teoría de los conflictos: si todo fuese sexual ¿dónde estaría el conflicto?

La teoría freudiana de la sexualidad comprendida como una unidad compleja demandaba una redefinición de lo que es la sexualidad "misma". Con anterioridad a Freud se la concebía como uno de los "instintos" y, en consecuencia a la realidad. Freud la humanizó, observando que en virtud de su carácter ideativo mental, tal como se manifestaba, sólo existía dentro del contexto de la cultura humana. En los Tres ensayos escribió que por "instinto", "debe entenderse provisionalmente, el representante psíquico de una fuente de estímulo endosomática que fluye constantemente...". [...] Freud expresó en más de una oportunidad que la conceptualización de un "instinto" (Trieb) estaba "en el límite de lo somático y lo mental"'1".

La pulsión no tiene objeto natural y, en consecuencia, lo que se considera como sexualidad normal —que siempre es relativa - tiene que desarrollarse a partir de las muchas pulsiones componentes de esta unidad compleja, que es la sexualidad humana. Cada componente, tanto por sí solo como con otros, puede quedar fijado en cierto punto, o puede ser objeto de regresión, siendo el resultado de cualquiera de estos acontecimientos la perversión o la neurosis. En cualquier caso, ningún componente es nunca totalmente abandonado, de modo que, incluso en la sexualidad normal, habrá un residuo de impulsos pervertidos que también pueden encontrar expresión en diversas formas como "perversiones menores" que, o son inadecuadamente reprimidos como síntomas neuróticos o, si se reacciona contra ellos con disgusto, vergüenza o moralidad, sus energías pueden reorientarse a esferas "superiores", produciéndose así la sublimación. Esta última es la base en el plano personal de la formación del superyo, punto crucial del carácter, la virtud, el éxito artístico, etc. y en el plano social es punto de partida de la socialidad, según Freud.

\section{Complejo de Edipo y deseo masculino y femenino}

Es precisamente la falta de objeto definido de la pulsión $\longrightarrow$ su dinamicidad, si se quiere- lo que constituirá el hilo conductor de las vicisitudes en el 
forjamiento de la identidad. Esto es precisamente lo que se quiere explicar con la célebre teoría del complejo de Edipo.

Según dicha teoría, el deseo más arraigado y, a la vez, el más reprimido dentro de todo sujeto y cultura es el del incesto, tanto es así que en el tabú del incesto Freud cree ver en el plano social el fundamento de la constitución de la sociedad y la moralidad. En el plano individual, la correcta superación del complejo de Edipo supondrá el establecimiento normalizado de la personalidad femenina o masculina y su carácter moral.

Todos hemos soñado alguna vez que se mueren nuestros padres y no sentimos ningún tipo de dolor o angustia. Este es el paradigma de nuestra situación en la familia cuando niños: el varón desea matar al padre y acostarse con la madre, como en la tragedia de Sófocles. Este deseo incestuoso hace surgir el temor de castración como expresión del miedo al castigo por tener como objeto de deseo a la madre. En la etapa fálica es donde se establece - según Freud- la elección del reconocimiento. El niño reconoce que el poder fálico de otro -el padre- es más grande y mejor que el propio. A partir de este reconocimiento tenderá ya no a rivalizar con el padre, como era el caso, sino a identificarse con él aceptando su superioridad y posponiendo sus deseos para más tarde, intemalizando de este modo las normas que prohíben a la madre. Este es un proceso muy angustioso para el niño, pues vive como una auténtica amenaza el sentimiento de que puede ser castigado con la pérdida de esta parte de su cuerpo; ansiedad que se ve reforzada por el hecho de descubrir, a través de las diferencias anatómicas entre los sexos, que "existen seres castrados", como son la mujeres, según nuestro autor. Pero precisamente por la potencia del terror es que el niño llega a internalizar la más elemental de las normas de la cultura. Gracias a éste es que se verá empujado a asumir su masculinidad, y lo vivo del temor es lo que lo impulsará a reprimir fuertemente su deseo, represión que redundará en beneficio de un superyo fuerte en el individuo masculino. Si a los tres o cuatro años ha logrado superar este conflicto, ya el niño deja de sentir atracción sexual por los padres y comienza a tener intereses extemos. Lo sexual entrará en una etapa de latencia para volver a hacer eclosión en la pubertad".

Ahora bien, ¿qué sucede con las mujeres? Esta es una pregunta que a menudo se hacía Freud para concluir rápidamente que en ellas todo es mucho más complicado. En primer lugar —señala—, las mujeres no tienen que temer la castración puesto que ya están castradas. El descubrimiento de que ellas no tienen pene las lleva a envidiarlo, pero como esto es algo que no podrán lograr, sustituyen esta envidia por el deseo de tener un bebé, especialmente un varón. Otra de las consecuencias de la envidia del pene sería la tendencia al narcisismo y una fuerte necesidad de ser amada como resultado de la constatación de inferioridad que produce en la mujer el saber que está privada de este miembro, y que lo estará siempre. 
Al sentirse castrada, de entrada, el superyo de la niña no necesita presentar una batalla tan severa a su impulso incestuoso. Esto es lo que hace - según Freud- que las mujeres tengamos menos inclinación a la competencia, a la creatividad, a las tareas científicas, etc. Al no tener que reprimir con tanta fuerza, como los varones, su deseo por los progenitores, las mujeres no desarrollan un superyo tan fuerte. Esta sería la causa de que a las mujeres nos falte el sentido de la justicia social y la conciencia que es la esencia del hombre civilizado, piensa Freud.

\section{La crítica feminista a Freud}

$\mathrm{Ni}$ qué decir tiene que esta teoría de la envidia femenina del pene ha sido fuertemente criticada. Por un lado, se aduce que es muy cuestionable el significado psicológico que para los infantes pueda tener el descubrimiento de las diferencias anatómicas entre los sexos. Por el otro, se advierte que Freud da por hecho que la mujer es -con obviedad- un hombre castrado ${ }^{12}$, sin cuestionar que tal envidia - si es que existe, lo que no queda ni mucho menos demostrado- pueda no estar referida al miembro viril, sino al hecho de que la posesión de tal miembro otorga una mayor jerarquía en la sociedad: son "ellos" quienes ocupan el lugar de poder en la familia, los que obtienen los cargos políticos y religiosos, los que perciben mayor atención y retribución, etc. Se critica, por lo tanto, a Freud el que no haga mayores referencias a lo social y convierta así una supuesta cuestión constructa en "sentimiento natural o innato", perdiendo ahí cierta parte de su potencial crítico, por lo menos visto desde una perspectiva feminista. Veamos esto más despacio, intentando senalar cuatro puntos de la doctrina freudiana que el feminismo cuestiona.

\subsection{Mito de la masculinidad primaria}

Freud define el sexo y la diferenciación sexual como presencia o ausencia de masculinidad y de genitales masculinos y no como dos presencias distintas. No nos dice tan sólo que la niña pequeña cree o imagina que está castrada, o que cree que es inferior por ser un niño incompleto. Nos dice que es así. Señala que la niña "descubre" que está castrada, que se niega a aceptar el "hecho" de estar castrada, que la mujer necesita ocultar su "deficiencia genital". Por tanto, la formulación del complejo de Edipo sería falsa de raíz si no aceptamos que la niña sea un muchachito sin saberlo, si rechazamos que el clítoris sea visto como un pene atrofiado, como sostiene la tesis de la masculinidad primaria ${ }^{13}$, tesis que, por otro lado, ha resultado ser biológicamente falsa.

Los prejuicios de Freud saltan a la vista en tanto en cuanto otorga una inferioridad a la mujer que no queda fundamentada, prejuicios que hacen incluso llegar a un psicoanalista a afimar que "debemos recordar el hecho de que la actividad sexual está asociada esencialmente al órgano masculino, de que la 
mujer sólo tiene la posibilidad de excitar la libido del hombre o de responder a ella y de que, de otro modo, está obligada a adoptar una actitud de espera"14. La descripción que Freud hace de las diferencias anatómicas no queda en el plano de la descripción, sino que hace juicios de valor que resultan en relaciones de superioridad e inferioridad que no brotan de una observación científica desinteresada y libre, sino de un sistema de valores patriarcal que él, conscientemente, deja sin cuestionar. El lenguaje de la "naturaleza" recubre posiciones patriarcales sobre la pasividad y la actividad y puede fundamentar una supuesta necesidad de los hombres de agredir sexualmente.

\subsection{Antifeminismo militante}

Freud no simpatizaba con las corrientes feministas de su época, y en sus conferencias se pone abiertamente en contra de las posiciones que exigen para las mujeres la equiparación de derechos, el acceso al espacio público y la capacidad de participar en política. Las que mantengan estas reivindicaciones serán conceptualizadas como "víctimas de una fijación en un estado infantil de envidia fálica"' . En este aspecto es continuador de las doctrinas médicas decimonónicas que sostenían la incapacidad biológica de las mujeres para la creación intelectual y la participación en la vida pública. Su discurso es, tal vez, más sutil que el de otros médicos, pero en definitiva iría a parar a lo mismo: a la diferencia de aptitudes innatas entre varones y mujeres. Esta visión parece contradecirse con su teoría de la bisexualidad que proveía una explicación a la variedad de personalidades existentes en ambos sexos y que tiende a representarse la variedad sexual como un continuo. En todo individuo - afirmará Freud- hay elementos "masculinos" y "femeninos" en proporciones diversas, sin embargo esto no lo lleva a dudar de que existen diferentes naturalezas"

Freud explica que a partir de la aparición de la envidia del pene, la evolución de la mujer puede tomar tres vías diferentes: negación de la sexualidad, masculinización con fantasías de igualdad con el hombre o realización de la naturaleza femenina en el matrimonio y la matemidad (en especial, si el hijo es varón y permite así a su madre obtener el pene que no posee). Alicia $\mathrm{H}$. Puleo advierte que: "este esquema con tres posibilidades de desarrollo del individuo de sexo femenino permite a Freud suministrar una explicación a distintas figuras de la mujer de principios de siglo: la frustrada, que por temor a la sexualidad evita el matrimonio; la sufragista, que pide el voto e iguales derechos que los hombres, y la mujer "normal", que encuentra su plena realización dentro del hogar y no aspira a salir de él"17.

El deseo de un hijo - la actitud femenina más "normal", si hemos de creer a Freud- proviene entonces de la envidia del pene, lo cual muestra cómo ni siquiera concibe la feminidad como ideal de posible identificación ni la matemidad —uno de los principales atributos de la feminidad y lo que más la diferencia 
biológicamente del varón- como nada más que envidia o complejo de inferioridad contra lo que es indiscutiblemente superior. A ello hay que objetar que si bien es cuestionable que el deseo por excelencia de la mujer sea tener bebés, por otro lo es más que en el supuesto de que exista este deseo, se lo catalogue como el deseo que tiene la mujer de ser masculina. Ya sus colegas mujeres protestaron en su momento por lo que ellas analizaban como claros prejuicios que llegan hasta el punto de hacerle exclamar: "Quizás debiéramos reconocer que el deseo del pene es el deseo femenino par excellence", o la expresiva afirmación de que uno de los resultados principales de la resolución del complejo de Edipo masculino es, y debe ser, "lo que hemos llegado a considerar el normal desprecio masculino por las mujeres"18.

\section{3. ¿Es más complicado llegar a ser mujer que varón?}

Freud confiesa abiertamente, en varios pasajes de su obra, que se le hace muy difícil entender a las mujeres. Para él, la constitución de la feminidad es de por sí más complicada que la de la masculinidad; sin embargo, para otros autores sería lo contrario, puesto que "la madre constituye tanto para el varón como para la nena un ideal temprano del género, razón por la cual el desarrollo psicosexual es más complicado para el varón que para ella, en lo que atañe al género"'19. Según sus detractores, en este punto esto vendría dado por el hecho de que tan central como la búsqueda del objeto de deseo resulta la valoración narcisista del género. Se trata de un problema de identificación, y el primer ser con el que se identifica el bebé, sea de uno u otro sexo, sería la madre. En este sentido, Nancy Chodorow propondrá una lectura mucho más social del coniplejo de Edipo, señalando que es importante subrayar que las madres propenden a experimentar a sus hijas como muy semejantes a sí mismas o, incluso, como continuaciones de ellas mismas. Análogamente, las hijas propenden a permanecer como partes de la primaria relación dual madre-niño.

La relación de apego a la madre suele ser más fuerte y continuada en la niña, porque las madres tienden a experimentar a sus hijos varones como opuestos, con lo cual es más probable que se expulse más tempranamente a los niños de la relación preedípica y que se vean obligados a recortar su amor primario y su sensación de lazos empáticos con la madre. El niño se entrega, y se le exige que se entregue, a una individuación más temprana, a una afimmación más defensiva de las fronteras del yo. A partir del mantenimiento del apego preedípico a la madre, las niñas llegarían a definirse y experimentarse como continuas con los otros; su experiencia del yo contendría fronteras yoicas más flexibles o permeables. Los niños, en cambio, se definirían como más separados y distintos, con una sensación mayor de fronteras yoicas rígidas. Desde este punto de vista, la sensación fundamental del yo femenino estaría más en conexión con el mundo; la del masculino, separada del mundo ${ }^{21}$. 
Los psicoanalistas señalan que todos los niños se deben liberar de la omnipotencia materna y conseguir una sensación de plenitud. El niño obtendría esta liberación mediante su masculinidad y la posesión de un pene. El pene y la masculinidad compensarían la temprana herida narcisista que le inflige el poder materno, y simbolizarían su independencia y distanciamiento de la madre.

La experiencia de una niña va a ser distinta en dos sentidos. Por un lado, la hija carece de algo distinto y deseable a lo cual oponer la omnipotencia maternal -cosa que el hijo posee-. Pero igualmente importante es el que "la madre no percibe a su hija del mismo modo que percibe a su hijo: no la ve como a un otro sexual sino como a un yo narcisísticamente definido"21. Una de las reacciones de la hija que intenta liberarse de la madre es el desarrollo de la envidia del pene, o de un deseo de pene para así tener algo que oponer a su madre, de la cual se quiere independizar.

Así es como Nancy Chodorow reinterpreta "feministamente" la cuestión de la envidia del pene. Esta envidia se situaría en un nivel metafórico: la niña lo desea por los poderes que simboliza y por la libertad que promete respecto a su previa sensación de dependencia, y no porque sea obvio ni inherentemente mejor ser masculina. La envidia del pene sería la expresión de otro deseo: el deseo de despegarse de la madre y convertirse en autónoma.

\subsection{La cuestión del narcisismo}

Toda personalidad para ser sana necesita desarrollar una estructura narcisista, su autoestima. Uno no puede amar si no se ama a sí mismo. A partir del estudio psicoanalítico de este hecho, Emilce Dio Bleichmar nos habla del "feminismo espontáneo de la histeria". La inmensa mayoría de las histerias se presentan en mujeres, y esta autora se dedica a constatar que a la mujer, en nuestra cultura, le resulta imposible $\longrightarrow$ muy difícil— narcisizar su yo porque hay una oposición entre feminidad y narcisismo.

La adolescente, a diferencia del varón, tendrá que vigilar su deseo, necesitará desarrollar controles para sus impulsos, pues las consecuencias que le puede acarrear el satisfacerlos pueden ser nefastas.

La virginidad constituye la expresión más pura de la estructura profundamente contradictoria del rol sexual exigido y esperado en la mujer. Si la conserva, mantiene el honor de su género, lo que eleva su narcisismo, pero permanece en un nivel de erotismo infantil que la hace sentirse incompleta; si por el contrario accede al deseo y su sexualidad se cultiva, creciendo como hembra, cae presa del tormento de perder al hombre y pasar a la categoría de mujer deshonrada o de verse compulsada a formalizar una unión precoz para evitar este riesgo, todo lo cual se halla lejos de hacer crecer su autoestima ${ }^{22}$. 
El problema, entonces, no se soluciona simplemente reprimiendo los impulsos, pues por otro lado tiene el dilema de necesitar desarrollar su feminidad en el terreno sexual, puesto que es precisamente por ello por lo que es paradójicamente valorada. Este es el motivo que la hace caer en la paradoja de desear el deseo y no su satisfacción. Esto "la mantiene a distancia de la acción concreta, de la vivencia, del goce, del aprendizaje y la madurez sexual"23.3 y, por tanto, en el fondo no se valoriza porque sabe de su inexperiencia, tiene inseguridad.

Este juego y rejuego de deseos y represiones abrirá la puesta a toda suerte de desequilibrios emocionales que darán paso a complicadas somatizaciones, personalidades infantiles o neurosis de distintos cortes, síntomas todos ellos que pueden ser catalogados como histéricos. Bleichmar se pregunta si justamente el malestar histérico no residiría en la reducción de la condición humana de la mujer a su sexualidad, a la superposición y confusión entre feminidad y sexualidad, a su ser social y su erotismo. Contradiciendo en cierto sentido a Freud, sugiere hacer una distinción entre sexualidad femenina y feminidad como rol social. "La feminidad no tiene que ver con el deseo sexual ni con ningún conjunto de pulsiones, sino con el conjunto de convenciones que cada sociedad sostiene como tipificadores de lo femenino y lo masculino. La conducta sexual de un hombre, su relación con la mujer, hablarán de su virilidad, pero la masculinidad de un hombre incluye valores como el coraje, la fuerza, la capacidad de decisión que podrán hacerlo más preciado a los ojos de una mujer, pero hasta ahora estos rasgos no parecen provenir de ningún substrato sexual, a menos que le otorguemos al pene estos atributos $[\ldots]^{\prime 24}$.

La histérica se interroga sobre todas estas cosas y luce su insatisfacción ante un orden ajeno que la tipifica como objeto, tipificación a la que se resiste. Privilegia la actividad sexual "para balancear su narcisismo, pero ello no implica que éste se reduzca a la sexualidad, sino que obviamente lo excede. Sustrayendo del escenario aquello por lo único que es tenida en cuenta -el sexo-, ¿será reconocida como algo más? En esta sustracción, en este rechazo se cuela su anhelo de valorización, su enigmático reclamo feminista". Es esto lo que lleva a Bleichmar a aventurar su tesis: "existe un feminismo espontáneo en la histérica que consiste en la protesta desesperada, aberrante, actuada, que no llega a articularse en palabras, una reivindicación de una feminidad que no quiere ser reducida a la sexualidad, de un narcisismo que clama por poder privilegiar la mente, la acción en la realidad, la moral, los principios y no quedar atrapado sólo en la belleza del cuerpo. Cuando en el hombre la valoración narcisista se plantea exclusivamente en el ámbito de la sexualidad surge igualmente la histeria masculina"'s. El síntoma histérico sería sinónimo de impotencia ante un estado de cosas que se hace insostenible ${ }^{2 \hbar}$. 


\subsection{Genitalidad y sexualidad}

Prosiguiendo con la enumeración de las críticas a Freud desde el feminismo y ya para terminar, podemos señalar también que deshace la tiranía de la genitalidad ampliando el concepto de sexualidad, pero algunos críticos afirman que no escapa a la tentación de la prescripción porque la "receta" que da es que un comportamiento normal es necesariamente un comportamiento "heterosexual": habla de la homosexualidad como una perversión, una anormalidad o un trastorno. "Esta ambivalencia — señala Weeks - muy estrechamente relacionada con ambigüedades parecidas en su actitud hacia la sexualidad femenina, no tiene por qué invalidar sus descubrimientos ${ }^{27}$, pero ciertamente nos hace poner en guardia sobre la "verificación" de los mismos. Sin embargo, al mismo tiempo hay que señalar que para su tiempo su actitud era bastante desprejuiciada - por lo que se refiere a la homosexualidad en este caso-, aunque no pueda escapar por completo de sus presupuestos normalizantes. En una carta a la madre de un joven homosexual se expresa así:

No hay duda de que la homosexualidad no supone ninguna ventaja; pero no hay que avergonzarse de ello, no es un vicio, ni es una degradación; no puede clasificarse como enfermedad; nosotros lo consideramos como una variación de la función sexual producida por cierta detención en el desarrollo sexual ${ }^{2 s}$.

Para concluir señalemos que uno de los aportes más importantes del psicoanálisis - junto con la afirmación de que la mayoría de los motivos de nuestras acciones se hallan ocultos, es decir, son inconscientes - ha sido el descubrimiento de la centralidad del placer dentro de la vida psíquica, centralidad que no hay que perder de vista a la hora de plantear una vida psíquica armoniosa o unas relaciones más plenas. Desde esta perspectiva se hace necesaria no sólo la liberacion exterior de las mujeres o de los homosexuales, esto es, la lucha que con tanto ahinco y coraje viene llevando a cabo desde hace tantos años el movimiento feminista en reivindicacion de nuestros justos derechos, sino tambien una liberacion interior ${ }^{29}$ que pasa por el discemimiento de nuestra situacion personal en el mundo, por la quiebra de nuestras más íntimas ataduras psicológicas, por la entrega a la conquista de nuestros desafíos, en definitiva, por un proceso vital no exento de peligros y de angustias, pero que sólo cada mujer puede hacer por sí misma.

\section{Referencias bibliogríficas}

Bleichmar, Emilce Dio. El feminismo esponténeo de la histeria. Adotraf, Madrid, 1985.

Chodorow, Nancy. El ejercicio de la maternidod. Gedisa, Barcelona, 1984.

Mitchell, Juliet. Psicoanálisis y feminismo. Anagrama, Barcelona, 1982 (2' ed.).

Weeks, Jeffrey. El malestar de la sexualidad. Talassa, Madrid, 1993.

Dowling, Colette. El complejo de Cenicienta. Grijalbo, Barcelona, 1982. 


\section{Notas}

1. Cfr. Nancy Chodorow, El ejercicio de la maternidad, pp. 217-218. Por ejemplo, cuando da por supuesto que la mujer, efectivamente, está castrada, o cuando al referirse a sus colegas mujeres les espeta: "Esto no se aplica a ustedes. Ustedes son la excepción; en este punto son más masculinas que femeninas", New Introdutory lectures, 1933.

2. Juliet Mitchell, Psicoanálisis y feminismo, p. 42, y agrega: "El éxito de Freud consistió en transformar la teoría biológica de los instintos en la noción de pulsión humana, en rastrear sus posibles expresiones y en asignarles un lugar dentro de la historia personal de la subjetividad. Fundamentalmente, los casos de Freud señalan que existe muy poca justificación para tratar las "etapas" como absolutas o incluso como separadas y secuenciales; [...][ćl mismo afirma que] el "instinto" es un concepto prestado ante el cual el psicoanálisis, por el momento, tiene que inclinarse, pero que puede ser considerado como una convención", p. 43.

3. Emilce Dio Bleichmar, El feminismo espontáneo de la histeria, p. 21.

4. Jeffrey Weeks, El malestar de la sexualidad, p. 212.

5. Freud, Introducción al psicoanálisis (Serie de lecciones), XXVIII, Terapia analítica 1916-17, citado por Juliet Mitchell, op. cit., p. 28.

6. Mitchell, op. cit., p. 58.

7. Freud, Tres ensayos para una teoria sexual. Juliet Mitchell señala que con el concepto de "bisexualidad" sucede lo mismo que con el de femenino y masculino en Freud: que "como muchas de sus ideas revolucionarias se originó con un presentimiento, fue cuestionado, recuestionado, modificado, considerado deficiente, y por último, restablecido como un concepto esencial", p. 63.

8. La idea freudiana de la biscxualidad siempre descansó sobre la bipolaridad del deseo, no del género. El niño freudiano, "pcrverso polimorfo y bisexual”, nunca fue concebido como el modelo del transcxual. Emilce Dio Bleichmar, p. 60: “desde el punto de vista psicoanalítico, el interés sexual exclusivo que sienten los hombres por las mujeres es también un problema que es necesario dilucidar, y no un hecho patente basado en una atracción que es, en última instancia, de carácter químico". Según Freud, los sentimientos homosexuales se manifiestan en personas heterosexuales, ya sea de forma latente o inconsciente. En un ensayo sobre Leonardo da Vinci, señala que el sentimiento homoscxual sublimado constituía un factor importante en la creación de vínculos grupales, desde la santidad en las órdenes sacerdotales, hasta el carácter masculino de las organizaciones militares (Weeks, p. 248).

9. Sin embargo, también es cierto que Freud tomó, durante bastante tiempo, el imperativo reproductivo como el fin del desarrollo de la sexualidad de un modo naturalista y teleológico (Weeks, p. 219).

10. Mitchell, op. cit., p. 41.

11. Según Freud, el temor es el que también hace que el hombre se vuelva violento y use la faja, por ejemplo (que es un símbolo fálico), o el palo, o lo que él considera atributos masculinos.

12. Teoria que está en relación con las doctrinas, parece que superadas, de la primariedad masculina de la especie.

13. Frente a esta crítica, Juliet Mitchell señala que los comienzos no son las conclusiones de Freud, que muchos críticos no advierten que sus intuiciones primarias después son reformuladas cambiando totalmente de significado. Según esta autora, Freud 
desafiará sus propias posicioncs y las corrcgirá, de modo que habría una antítcsis biológica entre los scxos: varones y mujercs, pero psíquicamente somos biscxualcs. En cualquicr caso hay que scñalar que en las posiciones de Freud hay una cicrta ambigüedad, se palpa que está a la búsqueda de su propia perspectiva, pero cllo no obsta para scñalar sus visibles prejuicios.

14. Karl Abraham, citado por Chodorow, op. cit., p. 218.

15. Ibid.

16. Ibid.

17. p. 69.

18. Freud, New Introductory Lectures, pp. 128-129; citado por Chodorow, p. 221.

19. Emilce Dio Blcichmar, p. 60.

20. Bleichmar, p. 252.

21. Chodorow, p. 184.

22. Dio Blcichmar, p. 147.

23. Bleichmar, p. 147.

24. Blcichmar, p. 211.

25. Bleichmar, p. 214.

26. A este respecto cabc recordar a Marilyn Monroc y tantas otras mujercs que pasaron por ser el estcreotipo de la feminidad y que pagaron con sus vidas la incapacidad de ajustarse a un guión absurdo. Cfr. Erncsto Cardenal, Oración por Marylin Monroe, Nueva Nicaragua-Monimbó, Managua, 1985.

27. Weeks, p. 244.

28. Weeks, p. 252.

29. Dowling, p. 35. 